\title{
TRES SANTUARIOS Y TRES MODELOS DE GESTIÓN TURÍSTICA EN LA MONTAÑA SAGRADA DE RANDA (MALLORCA) $)^{1}$
}

\author{
Margarita Novo Malvárez. \\ Miquela Forteza Oliver \\ Universitat de les Illes Balears
}

\section{RESUMEN}

El objetivo principal de esta investigación es estudiar los diferentes modelos de gestión turística de los tres santuarios localizados en la montaña de Randa (Mallorca), territorio en el que tienen cabida diversas espiritualidades y donde se distinguen diferentes fórmulas de entretenimiento y mercantilización de lo sagrado. La variedad de opciones que se materializan, indican una realidad dinámica y cambiante, extrapolable a otros lugares del ámbito internacional.

Palabras clave: turismo espiritual, patrimonio cultural, santuarios, ermitas, Ramón Llull

Three sanctuaries and three models of tourism management in the sacred mountain of Randa (Majorca)

\section{ABSTRACT}

The objective of this research is to study the different models of tourism management of the three sanctuaries located in the mountain of Randa (Mallorca), territory where different spiritualities can be found and where different formulas of entertainment and commercialization of the sacred are distinguished. The variety of materialized options indicate a dynamic and changing reality, extrapolated to other places in the international context.

Keywords: spiritual tourism, cultural heritage, sanctuaries, hermitages, Ramón Llull

Fecha de recepción: 7 de febrero de 2018

Fecha de aceptación: 24 de septiembre de 2018

Universitat de les Illes Balears. Ctra. de Valldemossa, km 7,5. 07122 Palma. ILLES BALEARS (España). E-mail:m.novo@uib.es,miquela.forteza@uib.es

1 Este estudio forma parte del capítulo de resultados correspondiente al proyecto de investigación «Estrategias documentales aplicadas a los procesos de restauración y divulgación del patrimonio artístico religioso de Mallorca» (HAR2015-66307-P), financiado por el Ministerio de Economía y Competitividad. 


\section{INTRODUCCIÓN}

La isla de Mallorca cuenta con gran cantidad de santuarios y centros religiosos de gran arraigo y tradición. Éstos se han convertido en símbolos de identidad para todos los mallorquines, especialmente para los habitantes de las localidades en donde se ubican estos santos lugares. Por regla general, cuentan con el valor añadido de poseer interesantes arquitecturas rodeadas de atractivos paisajes naturales que acentúan la sacralidad del entorno.

En la actualidad algunos de estos centros mantienen un modelo de gestión continuista, con predominio absoluto de la función religiosa tradicional, aunque con una menor actividad. Otros - los más innovadores - han ido realizando cambios para adaptarse a las nuevas necesidades de la sociedad y del mercado, tratando de sobrevivir en un contexto que puede calificarse de menos religioso pero más espiritual.

En este artículo se pretende analizar los modelos vigentes de gestión de los tres santuarios de la montaña sagrada de Randa: el santuario de Gracia, San Honorato y el santuario de Cura. El texto se ha estructurado en cuatro apartados, tres de contenidos y uno dedicado a las conclusiones.

El primero punto - que es de carácter introductorio - se centra en la definición del turismo espiritual. Se han establecido las concordancias y discordancias con otros segmentos turísticos con los que se les vincula, a saber, el turismo religioso y el turismo cultural. En Mallorca - territorio pionero a nivel turístico, especializado en una actividad turística de sol y playa - puede ser interesante prestar atención a este nicho turístico en expansión, el cual puede contribuir, sin duda, a completar y diversificar la gran oferta existente.

En el segundo apartado se analizan los lugares sagrados objeto de estudio. Se expone cuál ha sido su evolución desde el punto de vista turístico, cómo han ido cambiando y cómo - en todo momento - su imagen ha estado reforzada por la presencia de Ramón Llull, figura clave en el terreno de la espiritualidad. La estancia del místico mallorquín en la montaña de Randa ha sido determinante para intensificar la atracción del lugar y para reforzar su esencia espiritual.

En la tercera parte - que tiene un componente aplicado - se examina la gestión actual de los tres santuarios que conviven en la montaña de Randa. La diferencia existente entre los modelos de gestión de estos centros religiosos, muestra un panorama diverso, en donde se combina una oferta de perfil más tradicional (Santuario de Gracia) con otra más innovadora (Ermita de San Honorato y Santuario de Cura).

Para finalizar, se exponen unas conclusiones referentes a los impactos positivos y negativos del turismo en la zona. Estas deducciones pueden contribuir a una mejor planificación futura. En todo caso, es preciso que los cambios operados en estos centros religiosos - derivados de su adaptación a la contemporaneidad - tengan muy presente el respeto por la protección del patrimonio y la esencia espiritual del lugar. No hay que olvidar que ambos factores son los responsables de que durante siglos esos lugares hayan sido considerados especiales y que en ellos reside, precisamente, su mayor valor.

El objetivo principal de este trabajo es, por tanto, estudiar los diferentes modelos de gestión de los tres santuarios localizados en la denominada «montaña sagrada del Pla de Mallorca». Un escenario en donde tienen cabida diversas espiritualidades y donde se 
distinguen diferentes fórmulas de entretenimiento y mercantilización de lo sagrado. La variedad de opciones que se materializan, indican una realidad dinámica y cambiante, extrapolable a otros lugares de las Islas Baleares o incluso del Estado español. Es decir, se trata de una investigación de carácter local, pero que puede contribuir al estudio del turismo espiritual en general. Ambas lecturas permiten conocer cuáles son actualmente las dinámicas del mercado espiritual y religioso y cuáles son las principales transformaciones derivadas del aumento de este tipo de turismo y de la puesta en práctica de nuevos modelos de gestión.

La metodología utilizada es fundamentalmente de tipo cualitativo. La base de esta investigación, parte del reconocimiento de los santuarios y de la disertación con los responsables religiosos y/o turísticos de dichos lugares mediante la realización de entrevistas personales. Para la realización de estas entrevistas se ha diseñado un modelo de ficha compuesta por más de cincuenta preguntas, algunas muy precisas y otras de carácter más generalista. Las características de la oferta, el perfil y las motivaciones de la demanda, las bases económicas y de subsistencia, y el papel desempeñado por el patrimonio, protagonizan la mayor parte de las cuestiones formuladas a los responsables de los santuarios estudiados. En total fueron entrevistadas cuatro personas: dos miembros de la comunidad religiosa de San Honorato, el donado del Santuario de Nuestra Señora de Gracia y el director gerente del Santuario de Nuestra Señora de Cura. Estas entrevistas tuvieron una duración media de tres horas cada una. La información y los datos proporcionados fueron transcritos para su análisis y explotación posterior.

Esta investigación se completa con el análisis documental y estadístico recogido de instituciones relacionadas con el patrimonio en Mallorca y las Islas Baleares, -Dirección Insular de Patrimonio Histórico del Consell de Mallorca y la Dirección General de Turisme del Govern de les Illes Balears - , así como con la consulta de documentación en los archivos de los monasterios y en bibliotecas especializadas.

\section{EL TURISMO ESPIRITUAL, RELIGIOSO Y CULTURAL. CUESTIONES CONCEPTUALES Y TERMINOLÓGICAS}

El turismo religioso y el turismo espiritual son segmentos turísticos que están creciendo de manera exponencial tanto en países desarrollados como en países en vías de desarrollo. Los lugares de culto atraen cada vez a un mayor número de personas - tanto creyentes como no creyentes - como alternativa turística. La Organización Mundial de Turismo (OMT) estima que el turismo religioso y espiritual representa alrededor del $20 \%$ del turismo mundial, lo que significa que cada año entre 300 y 330 millones de turistas visitan los principales enclaves religiosos (Lanquar, 2007). Esta cifra - que influye tanto en el turismo nacional como en el internacional- convierte al turismo espiritual en un sector de gran relevancia para los estados, y de ella se deriva la atención que recientemente se le presta desde diferentes ámbitos (Conferencia Internacional de Turismo Espiritual de la OMT, 21 y 22 de noviembre de 2013, NinhBinh-Vietnam-). ${ }^{2}$

2 La primera Conferencia Internacional de Turismo Espiritual para el Desarrollo Sostenible se celebró en NinhBinh (Vietnam) en noviembre de 2013. Ésta giró en torno a la sostenibilidad y la gestión responsable de 
Antes de hablar de turismo espiritual es conveniente definir el término y diferenciarlo del turismo religioso. Se trata de conceptos relativamente recientes y polémicos, sometidos a diferente consideración por parte de los expertos en la materia. De esta forma, ciertos sectores académicos y religiosos entienden estos desplazamientos como actividades de fe en exclusiva, sin otorgarles un carácter turístico, ya que atribuyen al turismo cierta superficialidad frente a la autenticidad de la experiencia espiritual (Plaffenberger, 1983). No obstante, la realidad es que cada vez se acepta más la idea de que las personas que acuden a estos lugares, además de consumar sus inquietudes religiosas y/o espirituales suelen realizar otro tipo de actividades de carácter secular, las cuales pueden identificarse de manera clara con el consumo de bienes y servicios turísticos (Martínez Cárdenas, 2009).

El turismo espiritual ha sido definido como el desplazamiento de personas a un lugar en busca de una experiencia espiritual o la práctica de rituales de carácter místico que no tienen porqué tener un carácter religioso (Martínez Cárdenas, 2009). ${ }^{3}$ Por su parte, el turismo religioso limita este desplazamiento a los lugares sagrados, a una motivación primordialmente sacra. En consecuencia, el turismo espiritual abarca una concepción más amplia ya que todas las experiencias religiosas son espirituales, pero no todas las experiencias espirituales tienen porqué ser religiosas. La mayoría de los autores coinciden en este reconocimiento y afirman que el turismo religioso es solo un segmento del turismo espiritual. Así lo considera Rogelio Martínez Cárdenas, uno de los principales investigadores de este tema, quién distingue dos grandes grupos dentro del turismo espiritual: el turismo religioso y el turismo de reflexión (Martínez Cárdenas, 2009). Se entiende que no se trata de lo mismo por varios motivos: porque uno y otro tipo de turistas tienen motivaciones diferentes, comportamientos dispares y realizan el viaje en busca de experiencias distintas que, en el caso del turismo espiritual, acostumbran a ser más individualizadas. Esta circunstancia hay que relacionarla con el hecho de que la sociedad vive la religiosidad de una manera cada vez más individual y personal, factor que puede acabar acercando a los tradicionales turistas religiosos a las nuevas formas de espiritualidad que se prodigan en la etapa postmoderna.

Una vez establecida la distinción entre turismo religioso y espiritual, es fundamental reconocer la estrecha relación existente entre ambos tipos de turismo y el turismo cultural. Por regla general, ambos tipos de turistas comparten patrones y valores comunes entre los que destaca su interés y estima por el patrimonio (McGettigan, 2003). No en vano, la sociedad moderna suele combinar el placer religioso o espiritual con el consumo cultural y el disfrute de la naturaleza. Algunos autores consideran que el turismo religioso puede ser un subgrupo dentro del turismo cultural (Rinschede, 1992; Petrillo 2003).

El turismo espiritual se relaciona - en mayor o menor medida - con el turismo religioso y/o con el turismo cultural, aunque la necesidad de consumo cultural en el caso del turismo espiritual es sensiblemente menor. No obstante, no cabe duda, que este tipo de turismo crece a gran velocidad y cada vez gana más terreno a medida que lo pierden los rituales religiosos tradicionales. Lo exclusivamente religioso va perdiendo progresivamente la hegemonía de antaño para dar paso a otras opciones, a nuevas formas de

bienes naturales y culturales como medio de promoción del desarrollo socioeconómico de las comunidades y sociedades receptoras en todo el mundo.

3 De acuerdo con esta definición, una experiencia de este tipo puede ir desde una visita a una iglesia hasta la práctica de una actividad de relajación. 
espiritualidad que se desarrollan en un escenario cada vez más amplio y diverso. Como indica Jean Pierre Bastian, se asiste a un fenómeno de mutación religiosa que diversifica las formas de relación con lo sagrado, lo que lo libera, en cierta medida, del vínculo institucional (Bastian, 1997). La propuesta postulada en la década de 1990 por la socióloga inglesa Grace Davie — «creer sin pertenecer» — gana cada día más adeptos y conforma nuevos sistemas de creencias que se adaptan a las necesidades individuales y hace que se experimenten nuevas sensaciones (Davie, 2005). La autora pretende explicar que aunque muchos europeos continúan creyendo en un dios, no se identifican con la deidad propuesta por una determinada religión. Afirma que lo que la gente desea es una «religión indirecta», es decir una situación que sostenga los valores no observados en sus vidas pero que desean tener presentes. Actualmente son muchos los sociólogos de las religiones que se muestran de acuerdo con este análisis, el cual ofrece un panorama de sincretismo y de religión a la carta, en donde se aprecia un debilitamiento de la pertenencia religiosa. Massimo Introvigne - director del CESTUR (Centro de Estudios de las Nuevas Religiones de Turín) - confirma esta opinión afirmando que el fenómeno religioso más extendido es el de los que creen sin practicar una religión específica. Los antiguos modelos están dando paso a otros nuevos, en donde «están cada vez más presentes los caminos espirituales individuales, alternativos, esotéricos, volátiles y eclécticos» (Bahamondes, 2017: 70). Este fenómeno de flexibilización y diversificación religiosa se observa también en Mallorca. La emergencia de nuevas tendencias será estudiada en este artículo a partir del análisis de los diferentes modelos que tienen aplicación en los santuarios de la montaña de Randa.

\subsection{El turismo espiritual como objeto de debate}

Todas las polémicas e indefiniciones señaladas con respecto al turismo espiritual son debidas a la existencia de un debate que se ha gestado durante los últimos años a raíz de la toma de conciencia y reconocimiento de las potencialidades del sector. Hasta finales del siglo $\mathrm{XX}$, el turismo espiritual no tuvo un reconocimiento como segmento turístico diferenciado y apenas se le prestó atención. Como señala Silvia Aulet en la introducción de su tesis doctoral: «los trabajos del dominio teórico del turismo religioso son casi inexistentes hasta finales de la década de los 90 y comienzos del siglo XXI, momento en el cual se comienza a desvelar un interés creciente por el tema que se traduce en un aumento del número de publicaciones específicas» (Aulet, 2012: 23). De esta forma, autores como Erik Cohen o Boris Vukonic comienzan a estudiar el fenómeno religioso desde una perspectiva turística (Aulet, 2012).

Al mismo tiempo, se ha observado que el tema ha ido adquiriendo protagonismo en congresos y jornadas internacionales y en mesas de debate de ámbito local. En este sentido, ha sido fundamental la creación dentro de la institución ATLAS - dedicada a la investigación en turismo - de una mesa de trabajo específica dedicada al turismo religioso. Ello tuvo lugar en el año 2000 y, poco después, la Organización Mundial de Turismo (OMT) recogió el testigo dando nuevo impulso al debate con la organización de dos grandes conferencias internacionales. En 2007 se celebró en Córdoba (España) la Conferencia Internacional Turismo, religiones y diálogo entre culturas; y, en 2013, en NihnBinh (Vietnam), la Conferencia Internacional de NinhBinh sobre Turismo Espiritual. Como resultado de este segundo encuentro surgió la Declaración de NinhBinh sobre el Turismo Espiritual, que 
sirve de referencia para impulsar el turismo espiritual en todo el mundo a través de diferentes actuaciones. Entre las iniciativas propuestas destaca la potenciación de la investigación en materia de turismo espiritual en estrecha colaboración con las comunidades locales. Todas las actuaciones mencionadas unidas a las elevadas cifras de turistas demuestran que en la actualidad el turismo espiritual es una realidad consolidada. Por tanto, el debate ya no se centra en la discusión sobre su existencia sino que gira en torno al impacto que puede tener en términos económicos y sociales (Martínez Cárdenas, 2009).

\subsection{La consolidación del turismo espiritual como segmento turístico}

El escenario actual revela que las comunidades religiosas — una vez se han percatado de las ventajas que les puede reportar el turismo espiritual - son más proclives a promoverlo. Ello se materializa principalmente en un aumento de los ingresos que se destinan a mantener a sus miembros y a conservar los santuarios. Este escenario es también cada vez más amplio y complejo. En países como México, Chile o la India, el turismo espiritual ha conocido un desarrollo inusitado en las dos últimas décadas. Por su parte, en países europeos como Francia, Italia, Alemania, Chequia o España, no solo se ha despertado el interés por fomentar el turismo espiritual, sino que se está convirtiendo en un segmento turístico consolidado. Por un lado, ha aumentado mucho el número de personas que lo practican y, por otro, ha cambiado sensiblemente su perfil. Así, frente a la clientela tradicional de católicos que provenían de un ámbito relativamente próximo, local o nacional, se ha dado paso a un público más internacional mucho más variado y perteneciente a diferentes clases sociales (Lanquar, 2007). Elementos como la globalización, la reducción de los costes del transporte, los viajes combinados de grupos o los llamamientos de asociaciones religiosas o espirituales por Internet, han contribuido a favorecer esta internacionalización.

Una buena parte de los individuos que practican este tipo de turismo proceden del mundo urbano. Estas personas huyen del estrés de las grandes ciudades, buscando alternativas que favorezcan un reencuentro con sus raíces y costumbres, así como nuevas experiencias y respuestas en un entorno natural poco intervenido (Martínez Cárdenas, 2009). En definitiva, apuestan por una modalidad de turismo que les aporte paz y tranquilidad, disfrutándolo en lugares que cuentan con una nueva oferta religiosa basada en el consumo de bienes y servicios de carácter místico y espiritual (Bahamondes, 2013). Desconectarse del día a día, del ordenador, del móvil o del correo electrónico, puede ser la principal motivación para que un determinado tipo de viajero urbano opte por este tipo de turismo. En muchos casos estas condiciones son muy cercanas a las nuevas corrientes de viajes slow (tranquilo) o détox (en busca de la desintoxicación digital).

Los nuevos turistas espirituales reservan estancias cortas o medias haciendo uso de nuevos canales. Por lo general contactan con los centros (conventos, ermitas, hospederías monásticas, etc.) a través de sus propias páginas webs o de portales digitales de más amplio espectro. Éstos, se han convertido en las principales herramientas de promoción de las nuevas formas de mercantilización de lo sagrado (Vega- Centeno, 1995). Su proliferación es un buen indicador tanto del aumento de la demanda como del cambio en el perfil de los visitantes. Destacables son dos buscadores italianos de monasterios - Monastery Stays y Hospites - dedicados exclusivamente a ofrecer vacaciones y estancias en conventos de Italia. 


\section{Figura 1 \\ PORTAL DE BÚSQUEDA MONASTERY STAYS}

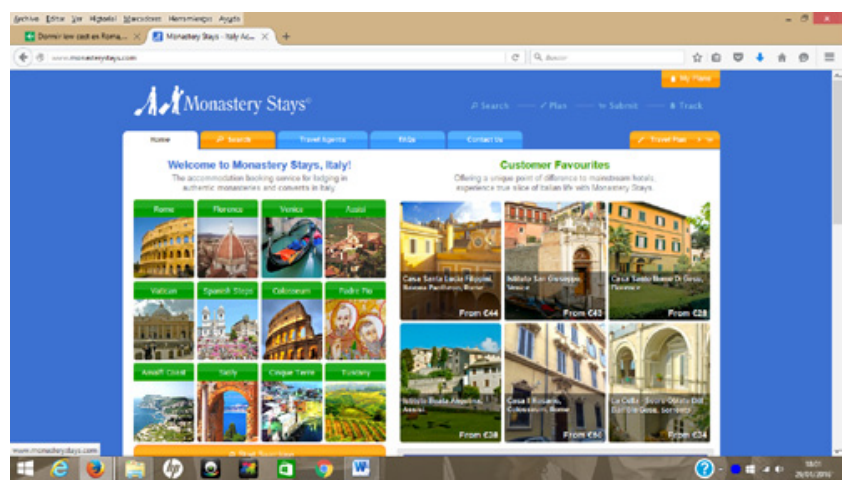

Fuente: http://www.monasterystays.com/.

En Alemania, Francia, Chequia o Escocia también existen herramientas de este tipo dirigidas fundamentalmente a gestionar las reservas de alojamiento a las personas que practican turismo cultural o turismo espiritual. En la mayoría de los casos facilitan la reserva del paquete completo, que incluye el alojamiento y las actividades de carácter espiritual ofertadas por los centros.

\section{Figura 2 \\ PORTAL DE BÚSQUEDA DE MONASTERIOS EN ALEMANIA}

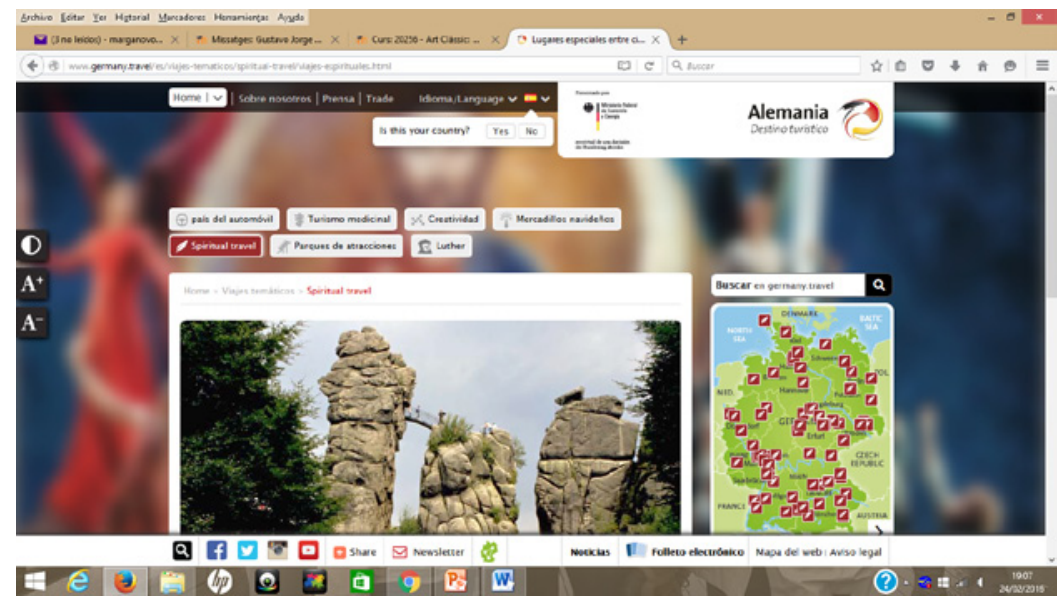

Fuente: Disponible en goo.gl/QQYF29.

En España, monasterios y santuarios constituyen un singular destino de vacaciones cada vez más solicitado por personas que practican turismo espiritual o turismo cultural. Los buscadores más populares de viajes y alojamiento - como pueden ser Trivago, 
Rumbo, LetsBonus o Booking - ofertan también estos retiros. De esta forma, el Santuario de Cura (Algaida, Mallorca) efectúa la mayor parte de sus reservas a través de Booking. $\mathrm{Su}$ adaptación a las nuevas fórmulas destaca la presencia de un nuevo perfil de cliente y los cambios en el tradicional modelo de gestión de los santuarios.

\section{LA TRADICIÓN EREMÍTICA DE LA MONTAÑA SAGRADA DE RANDA. LA MONTAÑA DE LOS TRES SANTUARIOS}

Según el diccionario Espasa, bajo la denominación de «ermita» se incluyen los santuarios y oratorios erigidos en lugares despoblados. Sin embargo, en Mallorca se denomina «ermita» únicamente a la casa en la que habitan los ermitaños (Un ermitaño, 1965). El término «eremitismo» viene del latín Eremus que significa «desierto». Se trata de la forma de vida de algunos cristianos que, renunciando a la vida en sociedad, se retiran a lugares deshabitados para dedicarse a la meditación, la oración y la penitencia. Son los llamados anacoretas, eremitas o ermitaños.

Según Pedro Ventayol en su Historia de Alcudia: «Es indudable que el Cristianismo se extendió por toda Mallorca desde el siglo I de nuestra Era. Aunque no hay documentos que lo acrediten, hay que suponer que durante los primeros siglos de nuestra era todos los montes estaban habitados por humildes Ermitaños» (Un ermitaño, 1965: 13-14).

Al parecer, el primer ermitaño de Mallorca fue Diego Espanyol instalado junto a las ruinas de un templo romano de la antigua Pollentia, donde construyó su ermita. Junto a ella se levantó otra de mayores dimensiones dedicada a Santa Ana (Un ermitaño, 1965: 14). No obstante, fue Ramón Llull quien implantó y popularizó la vida eremítica en la Isla

\section{Figura 3 \\ ESCULTURA DE RAMÓN LLULL. SANTUARIO DE CURA}

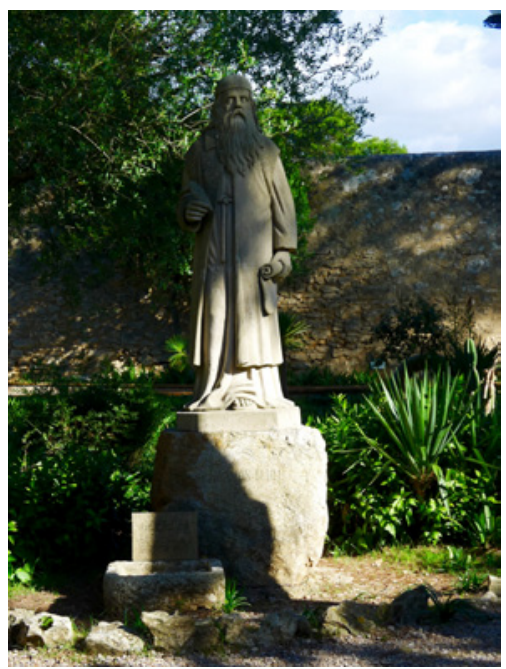

Fotografía: Elaboración propia. 
El Puig de Randa — situado entre los municipios de Algaida y Llucmajor en Mallorcaes la montaña principal y la que da nombre al macizo de Randa, en cuya cima -534 metros de altura - se halla el santuario de Cura. Los lugares elevados con frecuencia tienen una apariencia sobrenatural, un carácter trascendente porque participan directamente de lo sagrado, de lo celestial (Aulet, 2011). El Puig de Randa, cual montaña sagrada, además del de Cura, acoge otros dos santuarios: Nuestra Señora de Gracia y San Honorato.

Desde la época medieval este lugar ha sido un reclamo para ermitaños. Ramón Llull fue el primer mallorquín que, en torno a 1275, se retiró a la montaña de Randa para sumergirse en una vida eremítica. Vivió en una gruta cercana a la cumbre y se entregó por completo a la penitencia. Esta venerada cueva - que aún se conserva en parte - sigue siendo visitada por peregrinos y amantes del místico mallorquín. Aunque su permanencia en el lugar no fue muy dilatada en el tiempo, fue suficientemente intensa para que se quedara prendado del lugar y para que decidiera dedicar una pequeña ermita a la Virgen María.

La Vita coaetanea - extraída de las notas autobiográficas dictadas en 1311 por Llull a los cartujanos de Vauvert - es fundamental para conocer los acontecimientos primordiales de su vida. Thomas Le Myésier - uno de los lulistas franceses más convencidos - fue quien dio a conocer esta obra, incluida en el Electorium, y quien recopiló el Breviculum ex artis Remondi electum, ad preceptum regine Francie et Navarre sublimatum o Códice de Karlsruhe, ilustrado con doce magníficas miniaturas de principios del siglo XIV, las cuales contienen la filosofía y los principales acontecimientos de la vida del escritor y son el punto de partida de su iconografía. ${ }^{4}$ Gracias a esta obra se sabe que hasta los treinta años nuestro protagonista tuvo una vida convencional y mundana, la cual sufrió una profunda transformación a raíz de las cinco visiones de Cristo crucificado, acaecidas mientras estaba escribiendo unos versos amorosos en la montaña de Randa. Estas visiones cambiaron radicalmente su manera de vivir y de pensar, iniciándose a partir de entonces su acercamiento a Dios y su labor apologética (Forteza, 2016).

\section{Figura 4}

ENTRADA AL SANTUARIO DE CURA

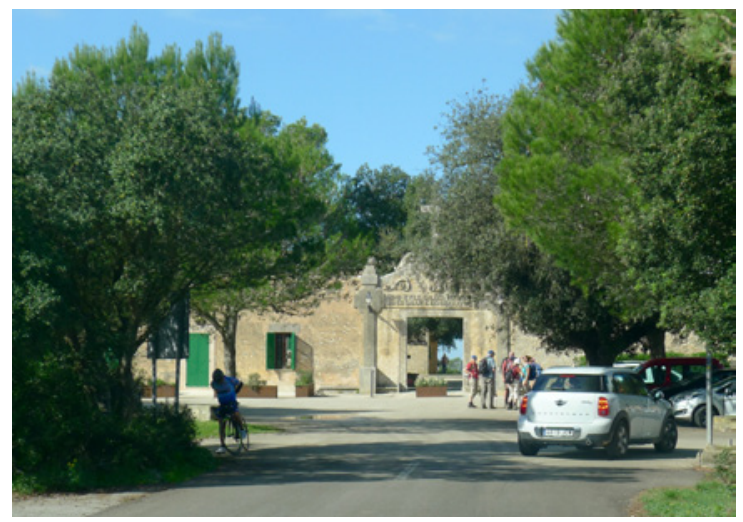

Fotografía: Elaboración propia.

4 Para más información sobre las miniaturas del Códice de Karlsruhe, véase: Sebastián, 1968. 
Ramón Llull es uno de los personajes más relevantes e ilustres de la cultura catalana y uno de los hombres más influyentes de la Europa medieval. Nació en 1232 en la ciudad de Mallorca y murió alrededor de 1315 o 1316. Según cuenta la leyenda, falleció a bordo de un barco rumbo a Mallorca después de haber sido martirizado por los sarracenos en el norte de África. Gracias a la intensa acción desarrollada por Llull y continuada por sus discípulos, la doctrina luliana se extendió por toda Europa, lo que motivó un importante movimiento editorial.

El ejemplo de Llull inspiró a otros anacoretas, quienes se retiraron a la montaña de Randa para estar más cerca de Dios. En la cima de la montaña se fueron edificando dependencias junto a la primitiva ermita, cuya imagen titular era conocida con el nombre de Nuestra Señora de Randa. No obstante, en 1549 se la cita ya como Nuestra Señora de Cura, al parecer debido a las múltiples curaciones que se obraban por su intercesión.

En la cima del Puig de Randa se ubica el Santuario de Nuestra Señora de Cura. La tradición atestigua que el origen del santuario está en el altar mariano que Ramón Llull hizo construir en 1275. Al parecer el doctor iluminado fundó lo que luego sería la Escuela de Gramática de Randa en una celda adjunta al altar dedicado a María. El santuario tuvo un gran protagonismo a partir del siglo XVI. La devoción por el lugar y la santa figura fue grande hasta el siglo XVII, momento en que empezó a menguar la asistencia. En 1826 se cerró el Aula de Gramática y con ello se extinguió el brillo del santuario y la devoción por el lugar. Su resurgimiento tuvo lugar en 1913 cuando el obispo Campins - gran devoto de Ramón Llull - dio un gran impulso a su culto y confió su custodia a los frailes franciscanos. En este mismo año se instauró la «bendición de los frutos» - celebración de religiosidad popular, de origen medieval, vinculada a la economía agraria - y la fiesta de Nuestra Señora de Cura. Coincidiendo con el boom turístico, sobre los años 60 se habilitó una hospedería y un restaurante, que han sido modernizados en 2014.

\section{Figura 5}

\section{SANTUARIO DE GRACIA}

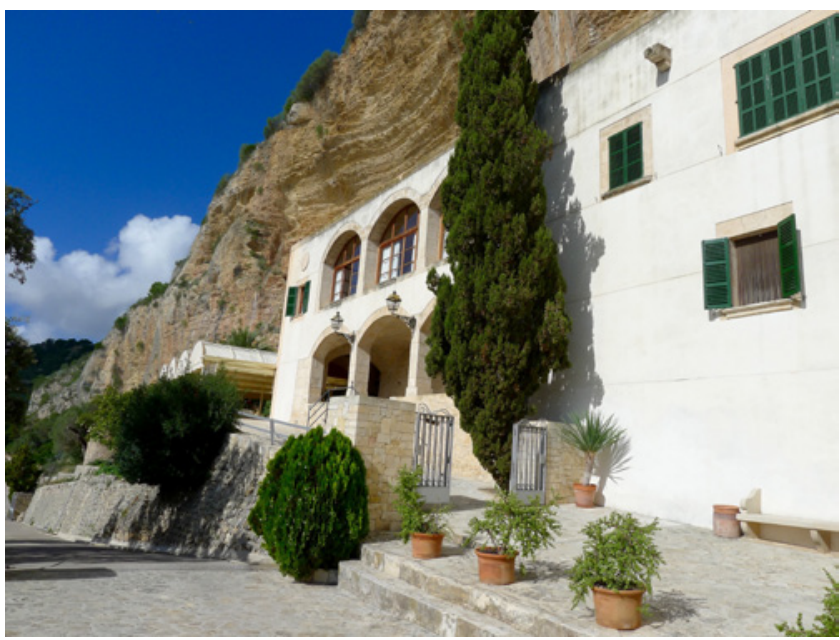

Fotografía: Elaboración propia 
Actualmente, el recinto del santuario - de gran interés patrimonial y turístico - está configurado por un convento, la iglesia, la antigua Escuela de Gramática - convertida en museo-, una hospedería, un restaurante y una tienda de recuerdos. Al margen de la belleza de su paisaje, su interés reside especialmente en su historia, historia ligada a la figura del místico mallorquín. No en vano, la gran portada que da acceso al recinto del santuario está presidida por un escudo de la orden franciscana de penitencia con una cruz con las iniciales OPC, tres clavos, la fecha 1682 y la siguiente leyenda extraída del libro de Blanquerna: «AMAB E FILL SALUDA NOSTA DONA QUI ES SALUT E BENEDICCIÓ NOSTRA. Blanq. Cap. 61. Pa. 7». El Santuario de Cura ha conciliado durante siglos la devoción mariana con la devoción luliana y el saber.

A los pies de la montaña, en pleno ambiente eremítico, se erigió una nueva ermita: el santuario de Gracia. Su historia empieza en 1440 cuando el franciscano Antonio Caldés decidió entregarse a la vida contemplativa. Junto a otro fraile, eligieron la enorme cavidad situada en la zona sur del monte sagrado para erigir una ermita. A la muerte de estos dos fundadores, otro religioso de la misma orden - Miguel Galmés - la amplió y añadió varias dependencias con el beneplácito de los propietarios de los terrenos (Un ermitaño, 1965). Galmés adquirió una imagen de la Inmaculada - que todavía se conserva - para un altar lateral de oratorio a la que llamó Nuestra señora de Gracia. Aunque en un principio el oratorio estaba dedicado a Santa Ana, en 1776 el obispo Díaz de la Guerra mandó que la imagen de la Virgen fuese colocada en el altar mayor en lugar de la santa titular. De hecho, desde muy pronto el santuario fue un centro de peregrinaje y de espiritualidad mariana.

El templo actual fue erigido en un intervalo de tiempo de casi dos siglos. Al parecer la primera piedra se puso en 1637 y no se acabó de construir hasta el 1819. Se trata de una pequeña iglesia de nave única y capillas laterales, cubierta con bóveda de cañón. Entre 1976 y 1983 fue ampliada la explanada que da acceso al santuario y se restauró la hospedería. Poco después - a raíz de una reforma - se hallaron los muros primitivos y el suelo de la primera iglesia en la actual capilla de santa Ana, así como los restos de un cementerio.

\section{Figura 6 \\ ERMITA DE SAN HONORATO}

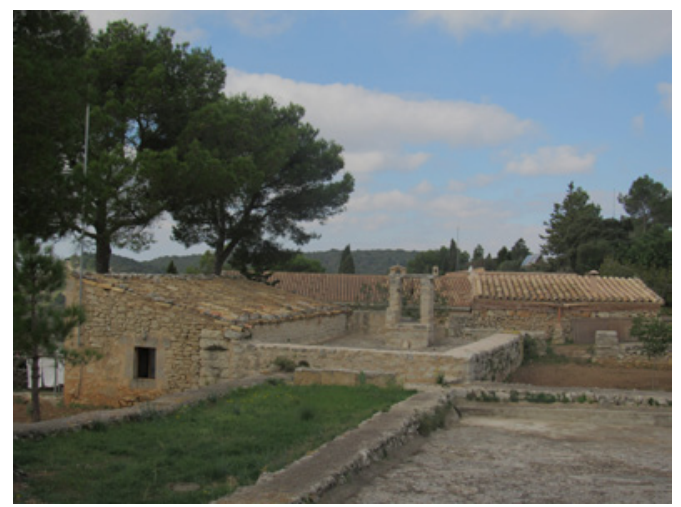

Fotografía: Elaboración propia 
La ermita de San Honorato fue también refugio de ermitaños desde la Edad Media. Está situada en la parte del mediodía de la montaña Randa, sobre la gran roca de Gracia, a mitad de camino entre Gracia y Cura. Los orígenes de la ermita se remontan al siglo XIV, concretamente a 1394, cuando Arnaldo Desbrull, _ quien había sustituido la espada por el sayal de eremita - pidió permiso al obispo Luis de Prades para que le concediera el permiso para levantar una ermita apropiada para albergar una comunidad. El 16 de enero de 1397 Blai Pou - domer de la Catedral de Mallorca - bendijo la primitiva capilla gótica, de la que únicamente se conserva una lápida situada sobre la portada de la actual iglesia, que dice así.

Hec capella quam edificavit

Fr. Arnaldus Desbrullio Heremita

Ad honorem Dei et Beati Honorati

auctoritate Reverendi Domini

Ludovici sedis Maioricarum Episcopi

Fuit solemniter benedicta per Blasium

de Puteo presbiterum die

Martis XVI januerii anno Domini

MCCCLXXXXVII. Deo gratias.

Esta fue la primera iglesia edificada en el Puig de Randa. En 1405 el obispo Prades concedió a los ermitaños licencia para construir una sepultura en la misma capilla a nivel de tierra - que todavía se conserva - para poder ser enterrados. En aquel tiempo los eremitas de San Honorato vivían en comunidad, dedicados a la oración y al trabajo, aunque no tenían voto estricto de pobreza (Munar, 1973).

El templo actual es también de pequeñas dimensiones, de planta basilical con capillas laterales y cubierta de bóveda de cañón. Fue construida entre1654 y 1661. Durante el siglo XVII y buena parte del XVIII fue administrada y protegida por los jurados de la villa de Algaida. Los ermitaños de san Pablo y san Antonio recuperaron el lugar en 1763.

En 1890 el sacerdote mallorquín Joaquim Rosselló Ferrà, de la Congregación del Oratorio de San Felipe Neri, se retiró a la ermita de San Honorato con la intención de dedicarse a la vida contemplativa. A Rosselló se le unieron un grupo de sacerdotes con los que formó una pequeña comunidad que el 17 de agosto de 1890 se convirtió en congregación religiosa clerical: la Congregación de los Misioneros de los Sagrados Corazones de Jesús y María de Mallorca, cuyas constituciones fueron aprobadas el 19 de marzo de 1891 por el obispo de Mallorca Jacinto María Cervera y Cervera. El cometido de la congregación es la vida contemplativa y activa y se expresa a través de retiros espirituales, misiones, educación cristiana de la juventud y ministerio parroquial. Actualmente, los misioneros de la congregación están presentes en diferentes partes de España, en Argentina, Camerún, Puerto Rico, República Dominicana y Rwanda, y siguen rigiendo y gestionando la ermita de San Honorato. 


\section{MODELOS DE GESTIÓN DE LOS SANTUARIOS DE LA MONTAÑA SAGRADA DE RANDA}

La realidad actual de los tres santuarios localizados en la montaña de Randa refleja la presencia de modelos diferenciados de gestión. Las prioridades, los objetivos y las metas perseguidos son distintos en los tres casos (Gracia, San Honorato y Cura). La mejor forma de ilustrar esta afirmación pasa por la lectura de las entrevistas realizadas a los responsables de la administración de los centros. A posteriori, se analizan brevemente las peculiaridades de la gestión de cada uno de ellos.

\subsection{Santuario de Nuestra Señora de Gracia}

Una vez iniciado el ascenso a la montaña de Randa el primer lugar sagrado con el que nos encontramos es el Santuario de Nuestra Señora de Gracia. Tradicionalmente ha sido un espacio muy accesible aunque, en la actualidad, permanece cerrado a la visita pública. La causa es que en enero de 2017 se produjeron desprendimientos en la zona destinada a aparcamiento que todavía no han sido reparados y que pueden suponer un peligro para los visitantes.

El santuario está gestionado desde hace más de cuarenta años por Sebastià Amengual - el donado más antiguo de Mallorca-, principal responsable de su mantenimiento y atención al público. El donado habita en unas estancias del propio recinto, lugar en el que se ha realizado la entrevista que se reproduce a a continuación:

Centro: Santuario de Nuestra Señora de Gracia (Llucmajor)

Persona entrevistada: Sebastià Amengual, donado del Santuario de Gracia (octubre 2017)

\begin{tabular}{|c|c|}
\hline $\begin{array}{l}\text { COMUNIDAD } \\
\text { Y PERSONAL } \\
\text { RESPONSABLE }\end{array}$ & $\begin{array}{l}\text { Orden: franciscana } \\
\text { Actualmente la comunidad de monjes no reside en el santuario. La crisis de } \\
\text { vocaciones obligó a los franciscanos a abandonar Gracia y a trasladarse al } \\
\text { convento de Llucmajor. Actualmente el santuario depende de la parroquia de } \\
\text { este municipio cuyo párroco, Eugeni Rodríguez, es el encargado del servicio } \\
\text { religioso. } \\
\text { Responsable principal del conjunto del santuario: el donado Sebastià } \\
\text { Amengual es el administrador del lugar. Él y su familia viven en una casa } \\
\text { acondicionada para tal fin en unas dependencias del santuario. Éstas les han } \\
\text { sido cedidas gratuitamente como compensación al trabajo desempenado, } \\
\text { consistente fundamentalmente en la vigilancia y mantenimiento del santuario } \\
\text { y en la ayuda prestada para la programación de actividades extraordinarias } \\
\text { que esporádicamente tienen lugar en Gracia. Asimismo, el donado realiza } \\
\text { trabajos de conservación del edificio supervisados por el arquitecto } \\
\text { diocesano. También se le permite regentar un negocio familiar centrado en la } \\
\text { organización de comidas para grupos. Generalmente se trata de celebraciones } \\
\text { particulares con un número mínimo de } 20 \text { personas y máximo de } 70 \text { (bodas, } \\
\text { comuniones, reuniones de catequistas, etc.). Los ingresos que le reporta esta } \\
\text { actividad constituyen su medio de vida. Para dar legalidad a esta labor, el } \\
\text { donado ha tenido que darse de alta en la Seguridad Social en el régimen de } \\
\text { trabajadores autónomos. }\end{array}$ \\
\hline
\end{tabular}




\begin{tabular}{|c|c|}
\hline CULTO & $\begin{array}{l}\text { Iglesia: depende de Llucmajor y está abierta diariamente. } \\
\text { Culto ordinario: solo se celebra misa algún domingo y días determinados } \\
\text { por petición especial. } \\
\text { Culto extraordinario: con relativa frecuencia se celebran bodas y } \\
\text { comuniones. La celebración extraordinaria más concurrida es la romería del } \\
\text { día del Ángel. }\end{array}$ \\
\hline ECONOMÍA & $\begin{array}{l}\text { La gestión económica del santuario está bajo la supervisión del donado. } \\
\text { Ingresos para el mantenimiento del lugar: provienen de donativos de } \\
\text { los excursionistas y de las actividades extraordinarias. En la actualidad el } \\
\text { santuario cuenta con un fondo que tiene una reserva económica de } 25.000 \\
\text { euros. }\end{array}$ \\
\hline $\begin{array}{c}\text { GESTIÓN } \\
\text { TURÍSTICA }\end{array}$ & 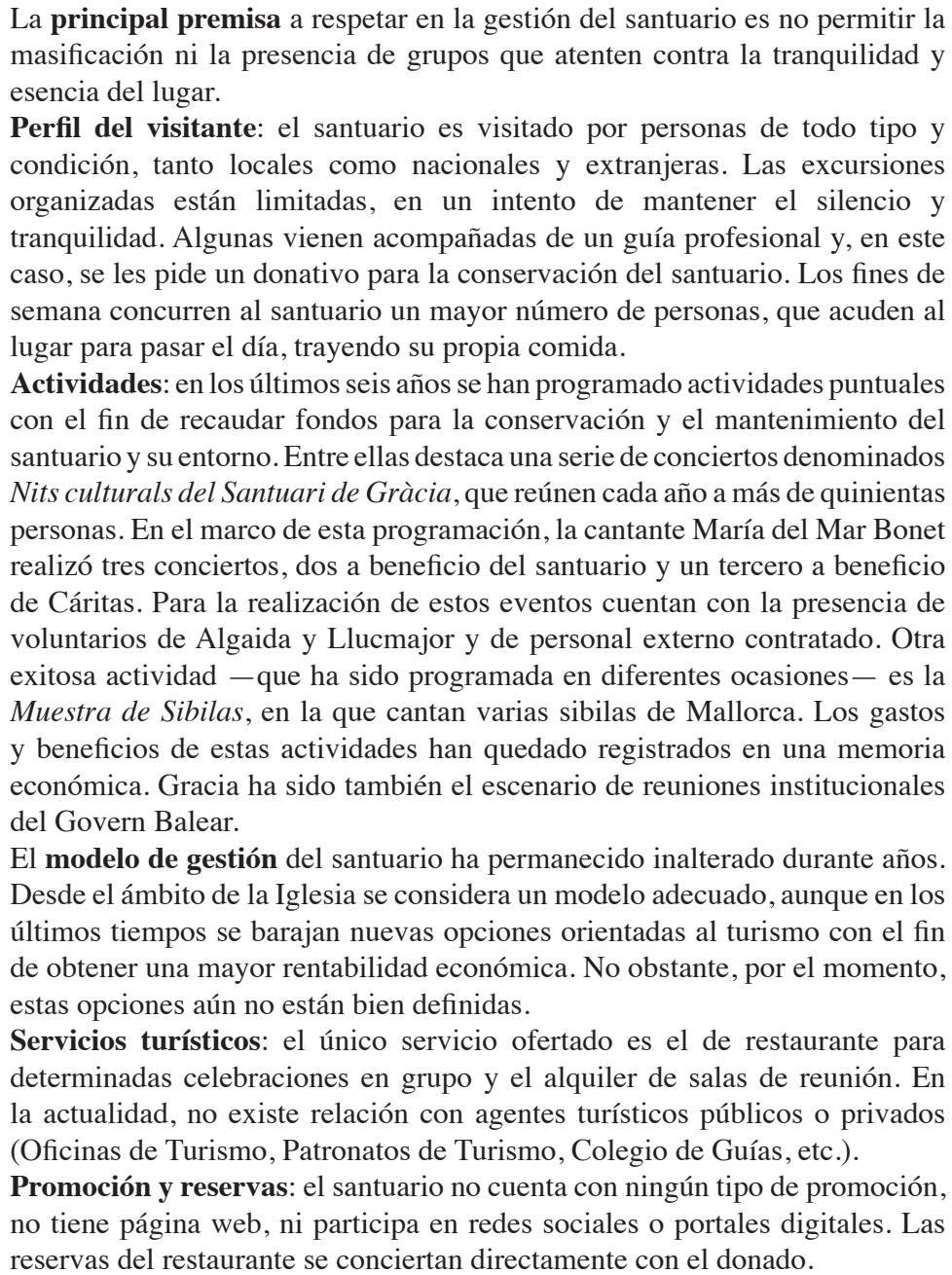 \\
\hline
\end{tabular}




\begin{tabular}{|c|c|}
\hline PATRIMONIO & $\begin{array}{l}\text { La población local se siente orgullosa del Santuario de Gracia, en especial los } \\
\text { vecinos de Llucmajor. } \\
\text { Accesibilidad: el acceso es libre siempre que sea para disfrutar del patrimonio } \\
\text { y se respete el silencio y la esencia del lugar. } \\
\text { Estado de conservación y problemas de mantenimiento: hasta comienzos } \\
\text { del año } 2017 \text { el santuario estaba muy bien conservado, tanto los edificios } \\
\text { como los jardines y huerto. En esta fecha se produjo un desprendimiento } \\
\text { y, desde entonces, permanece cerrado a la espera de que se realicen las } \\
\text { pertinentes obras de consolidación. } \\
\text { Edificio principal: la iglesia es el edificio más destacado del santuario. Ha } \\
\text { sido recientemente restaurada y presenta un buen estado de conservación. Es } \\
\text { el único lugar del santuario que siempre está abierto a la visita. } \\
\text { Junto a la iglesia se encuentra el antiguo monasterio en donde se ha dispuesto } \\
\text { una cocina grande, un salón comedor, una sala de reunión, la vivienda del } \\
\text { donado y un amplio porche. El archivo ha sido trasladado a la parroquia de } \\
\text { Llucmajor. }\end{array}$ \\
\hline $\begin{array}{l}\text { VISIÓN DE } \\
\text { FUTURO Y } \\
\text { REFLEXIÓN } \\
\text { FINAL }\end{array}$ & $\begin{array}{l}\text { Turismo espiritual: ¿segmento en auge o en crisis?: por regla general, las } \\
\text { personas que visitan el santuario no practican turismo espiritual sino que } \\
\text { responden al perfil de turista cultural. } \\
\text { ¿Por qué el Santuario de Gracia es un lugar especial?: por la fuerte carga } \\
\text { energética y simbólica del lugar. Un estudio realizado por geólogos de la } \\
\text { Universidad de les Illes Balears ha demostrado que los minerales de esta } \\
\text { montaña desprenden una energía especial. Asimismo, existe la creencia de } \\
\text { que Ramón Llull vivió aquí durante un tiempo. Una hipótesis respaldada por } \\
\text { la existencia en el lugar de una fuente y una cueva. } \\
\text { Con respecto al futuro del Santuario de Gracia, el donado considera que } \\
\text { estamos viviendo una etapa de cambio generacional que lleva asociada una } \\
\text { pérdida de religiosidad. El fuerte sentimiento religioso que ha imperado } \\
\text { hasta no hace mucho ha permitido que el santuario se haya mantenido en lo } \\
\text { substancial y que no se haya banalizado el espacio sagrado. En un futuro no } \\
\text { muy lejano, quizás el turismo se alce como una solución para la continuidad } \\
\text { del santuario. La clave está en establecer un programa de control para evitar } \\
\text { cualquier actuación que pueda suponer un perjuicio para el lugar. }\end{array}$ \\
\hline
\end{tabular}

Tras la lectura de la entrevista realizada al donado se constata que Nuestra Señora de Gracia, a pesar de ser un santuario sin comunidad que ha sucumbido hace años a la crisis de vocaciones, todavía mantiene la esencia sacra que le ha caracterizado desde sus inicios. De los tres santuarios localizados en el la montaña de Randa es el que ha permanecido menos adulterado, en el sentido de que se han operado pocos cambios en su modelo de gestión tradicional.

El donado es la figura en la que ha recaído la responsabilidad de la gestión del santuario a lo largo de los últimos cuarenta años. Su mayor mérito ha consistido en saber mantener la espiritualidad, evitando la preocupante banalización ocasionada por el turismo. Ello lo ha logrado priorizando la dimensión religiosa y espiritual sobre la turística, pero sin negar nunca el acceso al recinto a todo aquel que haya mostrado el respeto necesario que debe imperar en cualquier espacio sagrado. Otro mérito que hay que atribuir al donado es el excelente estado de conservación de todo el conjunto, incluyendo tanto las superficies 
construidas como las áreas verdes. Las buenas condiciones del lugar unido a su sacralidad han permitido que los habitantes de Llucmajor y, por extensión, todos los mallorquines, se muestren orgullosos de este santuario con el que se sienten fuertemente identificados.

Desde un punto de vista económico Gracia ha sido autosuficiente y continúa siéndolo aunque, su actividad lucrativa, cultural y religiosa ha sido limitada. En la actualidad, la situación económica ha empeorado por el cierre temporal del recinto sagrado que ha paralizado por completo su ya reducida dinámica. Las nuevas tendencias y las experiencias puestas en marcha en lugares de características similares nos llevan a considerar la probabilidad de que, en un futuro no muy lejano, la gestión del Santuario de Gracia se oriente hacia una mayor explotación turística con el fin de obtener una mayor rentabilidad económica.

\subsection{Ermita de San Honorato}

Continuando el ascenso por la montaña de Randa se halla la ermita de San Honorato, un lugar singular por su gran espiritualidad. Desde hace unos años ha alcanzado mucho renombre en el conjunto de Mallorca. La ermita, la hospedería y las actividades espirituales y de meditación programadas en San Honorato son el motivo por el cual llegan hasta aquí numerosas personas - mayoritariamente extranjeras - que conviven con una comunidad mixta compuesta por religiosos y laicos que ofrecen un servicio espiritual, altamente demandado.

La comunidad gestora de la ermita de San Honorato ha respondido a muchas cuestiones relacionadas con el turismo y la espiritualidad, detallando ampliamente los pormenores de esta relación. Sus miembros prefieren usar el término «huéspedes» en lugar de «turistas» para designar a los visitantes del lugar. Las preguntas formuladas y las respuestas obtenidas en esta casa de oración se exponen a continuación:

\begin{tabular}{|c|c|}
\hline \multicolumn{2}{|c|}{$\begin{array}{l}\text { CENTRO: Ermita de San Honorato (Algaida) } \\
\text { PERSONAS ENTREVISTADAS: María Gener, miembro laico de la comunidad e Hippolyte Voka, } \\
\text { Padre Superior de la comunidad. (octubre 2017) }\end{array}$} \\
\hline $\begin{array}{c}\text { COMUNIDAD } \\
\text { Y PERSONAL } \\
\text { RESPONSABLE }\end{array}$ & $\begin{array}{l}\text { Orden o Congregación: Misioneros de los Sagrados Corazones de Jesús y María. } \\
\text { La congregación se fundó en San Honorato en } 1890 \text {. El fundador fue Joaquín } \\
\text { Roselló i Ferrà. Este lugar tiene una larga tradición eremítica. } \\
\text { Número de miembros: } 5 \text { ( } 3 \text { religiosos y } 2 \text { laicos). Desde } 2011 \text { se ha permitido la } \\
\text { inclusión de personas laicas. Anteriormente la comunidad era más numerosa pero } \\
\text { la crisis de vocaciones ha provocado su descenso. } \\
\text { Edad media: } 40-60 \text { años } \\
\text { Procedencia: un congolés, un murciano, un menorquín, un mallorquín y una } \\
\text { mallorquina. En la comunidad hablan catalán, español e inglés. } \\
\text { Perfil de los miembros: los miembros de la comunidad se autodefinen como } \\
\text { practicantes de vida espiritual. No son cuidadores de la casa, sino que tienen una } \\
\text { vida espiritual basada en la oración y meditación. Su objetivo prioritario es cultivar } \\
\text { la espiritualidad, a veces en grupo, a veces en soledad. } \\
\text { Relación miembros de la comunidad con los huéspedes: hay una relación } \\
\text { bastante estrecha entre los miembros de la comunidad y los huéspedes debido a la } \\
\text { participación en actividades comunes (rezos, comidas...). Esta relación se remonta } \\
\text { tiempo atrás, ya que San Honorato tiene un largo pasado de tradición hospedera. En } \\
\text { la década de } 1980 \text { ya acogían a grupos espirituales. }\end{array}$ \\
\hline
\end{tabular}




\begin{tabular}{|c|c|}
\hline CULTO & $\begin{array}{l}\text { La iglesia siempre permanece abierta. Cada tarde de la semana se celebra misa, } \\
\text { excepto los domingos que se oficia por la mañana. La misa dominical es la más } \\
\text { concurrida y a ella acude gente de los municipios vecinos. } \\
\text { Dentro del culto extraordinario destaca la gran demanda que hay para la } \\
\text { celebración de bodas. Buena parte de ellas son de alemanes, a veces incluso } \\
\text { oficiadas por sacerdotes luteranos. Otra celebración extraordinaria es la que se } \\
\text { hace en enero, en honor del patrón, San Honorato. } \\
\text { Las actividades de culto y las de meditación tienen un horario regulado. Cada } \\
\text { mañana de } 6.30 \text { a } 7.30 \text { tiene lugar la meditación y de } 7.30 \text { a } 8.00 \text { el laudes. Por la } \\
\text { tarde de } 19.00 \text { a } 19.30 \text { otra vez meditación y a las } 7.30 \text { comienzan las vísperas que } \\
\text { dan paso a la celebración de la misa. }\end{array}$ \\
\hline ECONOMÍA & $\begin{array}{l}\text { Intermediarios, donados, servicio externo: la comunidad asume la realización } \\
\text { de todas las actividades cotidianas a excepción de lo relacionado con la cocina } \\
\text { y limpieza. Para estos servicios tienen contratada una cocinera a media jornada } \\
\text { - de lunes a viernes - y una limpiadora, tres días por semana. Por su parte, los } \\
\text { grupos colaboran voluntariamente con la comunidad participando en diferentes } \\
\text { tareas (cultivo del huerto, pequeñas obras de mantenimiento, etc.). En ocasiones, } \\
\text { también acogen a reos que realizan trabajos para la comunidad a cambio de una } \\
\text { reducción de condena. } \\
\text { No tienen ayudas económicas de la Iglesia ni de otros organismos, pero tampoco } \\
\text { les interesa especialmente porque su cobro implicaría una pérdida de libertad. } \\
\text { Ocasionalmente lo que sí perciben son donativos por parte de algún huésped. } \\
\text { La hospedería les ayuda a soportar los gastos económicos. Los ingresos derivados } \\
\text { de este servicio se reinvierten en el mantenimiento de la comunidad, en la } \\
\text { conservación del patrimonio y en causas sociales. El precio del alojamiento por } \\
\text { persona es orientativo y oscila alrededor de } 52 \text { euros, con comida incluida. Este } \\
\text { precio es exclusivo para mallorquines ya que para los extranjeros es más elevado, } \\
\text { unos } 60 \text { euros diarios. No obstante, algunas personas que no pueden pagar son } \\
\text { acogidas igualmente, de manera gratuita. }\end{array}$ \\
\hline $\begin{array}{c}\text { GESTIÓN } \\
\text { TURÍSTICA }\end{array}$ & $\begin{array}{l}\text { Perfil del huésped/turista: los huéspedes/turistas son religiosos o laicos que se } \\
\text { integran en la vida de la comunidad y comparten sus rutinas y actividades (oración, } \\
\text { meditación, comida, cánticos, talleres...). Algunos no son cristianos. Además de } \\
\text { personas individuales, acuden también grupos compuestos por una media de } 25 \\
\text { individuos generalmente liderados por un responsable. Muchos grupos repiten } \\
\text { cada año. Estas personas no acostumbran a salir del recinto. Su prioridad es la } \\
\text { meditación a la que dedican entre cuatro y cinco horas diarias. A veces están varios } \\
\text { días meditando en silencio completo. Algunos también practican la desconexión } \\
\text { digital. } \\
\text { Procedencia, clase social: los huéspedes de San Honorato son principalmente } \\
\text { extranjeros, con un claro predominio de alemanes, quienes proyectan la estancia } \\
\text { en San Honorato como parte de sus vacaciones sufragadas, en ocasiones, por } \\
\text { la empresa en donde trabajan. No se admiten niños, pero sí adolescentes que } \\
\text { participan en actividades de meditación. La mayoría de las personas que componen } \\
\text { los grupos son de clase media. Entre los que llegan individualmente el panorama } \\
\text { social es un poco más diverso. } \\
\text { Servicios que ofertan: los servicios que se ofertan en San Honorato son para } \\
\text { disfrute exclusivo de los huéspedes: hospedaje (celdas), salas de reunión y } \\
\text { meditación, y servicio de comida. Las comidas están incluidas con el hospedaje, } \\
\text { y generalmente se preparan platos vegetarianos, a veces con productos del propio } \\
\text { huerto. }\end{array}$ \\
\hline
\end{tabular}




\begin{tabular}{|c|c|}
\hline $\begin{array}{c}\text { GESTIÓN } \\
\text { TURÍSTICA }\end{array}$ & 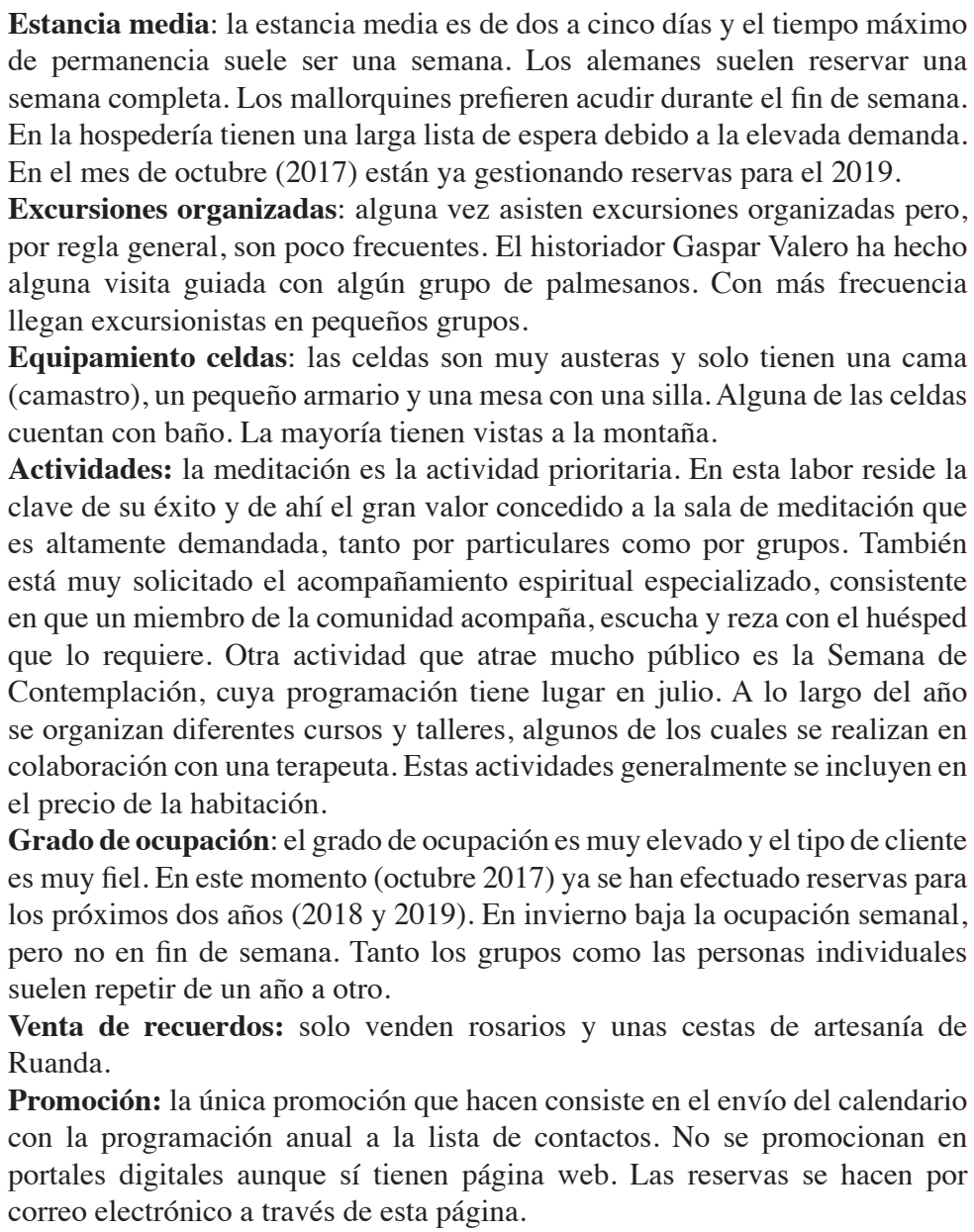 \\
\hline PATRIMONIO & $\begin{array}{l}\text { Accesibilidad: el acceso es abierto, es decir, no impiden la entrada a nadie que } \\
\text { acuda al lugar para disfrutar del patrimonio, siempre que respete el clima de } \\
\text { silencio. } \\
\text { Estado de conservación: los edificios y su entorno inmediato presentan un buen } \\
\text { estado de conservación. Los medios para el mantenimiento proceden del dinero } \\
\text { que se obtiene de las estancias de los huéspedes. } \\
\text { Espacios más relevantes: } \\
\text { Sala de Meditación: este es un espacio común que todos pueden utilizar, no solo } \\
\text { los religiosos. En origen, esta sala fue un antiguo gallinero que ha sido reformado } \\
\text { en varias fases. } \\
\text { Ermita: la ermita se construyó en } 1860 \text {. Anteriormente fue una cuadra para } \\
\text { animales y hoy es un espacio para el retiro. En ella hay dispuesto un rincón de } \\
\text { plegarias con una cama y una pequeña cocina. Algunos miembros de la comunidad } \\
\text { llegan al lugar para aislarse temporalmente, buscando soledad y silencio. }\end{array}$ \\
\hline
\end{tabular}




\begin{tabular}{|c|c|}
\hline PATRIMONIO & $\begin{array}{l}\text { Iglesia: la iglesia permanece diariamente abierta al público. } \\
\text { Celdas para huéspedes: las celdas son habitaciones muy sencillas acondicionadas } \\
\text { para el descanso de los huéspedes. En total hay veinticinco, de las cuales cuatro son } \\
\text { dobles. Las celdas adaptadas para minusválidos están en la zona de la comunidad. } \\
\text { Celdas para la comunidad: la comunidad utiliza seis celdas. } \\
\text { Cocina y comedor: la cocina y el comedor están contiguas y se caracterizan por } \\
\text { su simplicidad. } \\
\text { Cementerio: el cementerio es relativamente pequeño aunque aquí se enterraron } \\
\text { muchos monjes. También cuenta con un panteón donado por una familia de } \\
\text { Manacor. } \\
\text { Monumento a las religiones: La comunidad se muestra orgullosa de este bien, una } \\
\text { pieza escultórica realizada a partir de una antigua rueda del carro de los ermitaños } \\
\text { que, de alguna manera, se ha convertido en símbolo del lugar. } \\
\text { Biblioteca: en el piso superior de la hospedería hay una biblioteca de acceso libre } \\
\text { que guarda obras principalmente de temática religiosa. }\end{array}$ \\
\hline $\begin{array}{c}\text { VISIÓN DE } \\
\text { FUTURO Y } \\
\text { REFLEXIÓN } \\
\text { FINAL }\end{array}$ & $\begin{array}{l}\text { Turismo espiritual ¿Segmento en auge o crisis?: los miembros de la comunidad } \\
\text { de San Honorato consideran que el turismo espiritual está en auge debido al } \\
\text { aumento de la espiritualidad. No obstante, son reacios a utilizar el calificativo } \\
\text { de «turismo espiritual» pues, para ellos, el término turismo es peyorativo y } \\
\text { consideran que aquel que viene a San Honorato tiene unas inquietudes espirituales } \\
\text { y no turísticas. Se definen como una casa de espiritualidad católica dedicada a la } \\
\text { meditación y a la oración, aunque con una dimensión interreligiosa. Consideran } \\
\text { que su modelo es totalmente contrapuesto al del Santuario de Cura, al que califican } \\
\text { de empresa turística. } \\
\text { ¿Por qué es un lugar especial?: consideran que San Honorato es un lugar especial } \\
\text { por el silencio y la paz que se respira, vinculada tradicionalmente a la oración y a la } \\
\text { vida eremítica. En } 1370 \text { está constatada la presencia de los dos primeros ermitaños } \\
\text { y en } 1900 \text { se marcharon los últimos. Consideran muy significativa la oración en } \\
\text { contacto con la naturaleza. Creen que algunos lugares - como el mirador- poseen } \\
\text { una fuerte carga energética y espiritual emanada de la montaña. Otros atractivos } \\
\text { son el silencio y la propia comunidad. En este sentido consideran significativa la } \\
\text { presencia en la montaña de Ramón Llull, quien contribuyó a dar proyección al } \\
\text { lugar. En San Honorato creen que fue aquí donde tuvo lugar su iluminación. }\end{array}$ \\
\hline
\end{tabular}

El análisis de la información obtenida a partir de las entrevistas realizadas en San Honorato indican que se trata de un lugar que prioriza la espiritualidad por encima de cualquier otra actividad. La combinación de oración con meditación y trabajo centra la vida de la comunidad y los huéspedes, los cuales no acostumbran a salir del recinto, y, por tanto, no practican el turismo cultural. Ambos grupos comparten espacio y tiempo, estableciendo una relación de cercanía que no se da entre comunidad y población local.

La actividad religiosa es también intensa ya que se celebra un culto diario. Cabe señalar que San Honorato es un centro abierto a prácticas religiosas no exclusivamente católicas, lo que contribuye a su singularidad y a aumentar la demanda, sobre todo de personas extranjeras. 
La propia comunidad ha evolucionado de religiosa a mixta, a pesar de que el número de miembros se ha visto reducido a causa de la crisis de vocaciones. Ésta se ocupa de la gestión religiosa y empresarial, factor que marca la diferencia con respecto a los santuarios vecinos. Una gestión que se revela eficaz ya que les permite no solo ser autosuficientes sino incluso tener un buen nivel de ingresos que ayudan a mantener el patrimonio en buen estado de conservación. La clave del éxito reside en la programación de una oferta espiritual en un entorno que destaca por su patrimonio natural y cultural, y que cuenta también con un servicio de hospedería para dar cobertura completa a aquellas personas que buscan disfrutar de un retiro espiritual. En definitiva, se trata de un lugar con una oferta diferenciada y altamente demandada.

\subsection{Santuario de Nuestra Señora de Cura}

El Santuario que preside la cima de la montaña de Randa es el de Nuestra Señora de Cura. En el Puig de Randa se encuentran el santuario y la cueva en la que se cree que se retiró a meditar el beato Ramón Llull. Ambos fueron declarados Paraje Pintoresco en 1951 y tienen el rango de Bienes de Interés Cultural. En la actualidad se ha convertido en un centro receptor de visitantes que practican turismo cultural. Los turistas que llegan a Cura pueden pasar el día en los alrededores, comer en su restaurante e incluso dormir en la antigua hospedería monástica que ha sido recientemente remodelada para convertirse en un hotel de calidad. Además, también tienen la posibilidad de visitar un museo muy particular. Éste alberga la antigua Aula de Gramática que se creó a principios del siglo XVI a instancias de la Escuela Luliana establecida en el Estudio General de la ciudad de Palma para dar oportunidad de aprender Gramática, Retórica y Griego a centenares de estudiantes internos en este lugar. El museo - que hace continua referencia a la figura de Ramón Llull y que contiene gran cantidad de libros impresos y manuscritos relacionados con el lulismo - alberga también una interesante colección de piezas de etnología popular mallorquina junto a obras religiosas y litúrgicas relacionadas con la historia del santuario. Otro atractivo del lugar es la cueva del místico mallorquín - de titularidad privada - la cual va a ser abierta al público tras un acuerdo de febrero de 2018 de colaboración con sus propietarios. El Consell y el Ayuntamiento de Algaida serán los encargados de gestionar este espacio protegido. ${ }^{5}$

La iglesia, continúa a cargo de la antigua comunidad religiosa de franciscanos de la Orden Tercera Regular, mientras que el hotel y el restaurante son dirigidos por una empresa privada que, no obstante, no olvida que actúa en un lugar público y sagrado. La entrevista realizada al director gerente de esta empresa se reproduce a continuación.

5 «El acuerdo estará vigente hasta el final del 2019 y a partir de entonces se prorrogará anualmente, siempre y cuando una de las dos partes no comunique lo contrario. Los propietarios deberán ceder las llaves de acceso al recinto de la cueva al Consell y al Ajuntament y permitir las visitas a la cueva. Por su parte las dos instituciones deberán mantener en buenas condiciones la zona y el camino de acceso además de encargarse de la vigilancia y mantenimiento de todo el recinto». Ultima Hora, 25/02/2018 [En línea: goo.gl/2h1uTr, consulta: 15-09-2018]. 


\begin{tabular}{|c|c|}
\hline \multicolumn{2}{|c|}{$\begin{array}{l}\text { CENTRO: Santuario de Nuestra Señora de Cura (Algaida) } \\
\text { PERSONA ENTREVISTADA: Rafael Vidal, director gerente del restaurante y la hospedería. }\end{array}$} \\
\hline COMUNIDAD & $\begin{array}{l}\text { Orden o Congregación: franciscana, Orden Tercera Regular. } \\
\text { Los monjes solo se ocupan de las cuestiones religiosas (culto). } \\
\text { Relación miembros de la comunidad con los huéspedes: la relación entre } \\
\text { religiosos y huéspedes es escasa porque los miembros de la comunidad ya } \\
\text { no residen en el santuario, únicamente acuden al lugar para celebrar los actos } \\
\text { litúrgicos. }\end{array}$ \\
\hline CULTO & $\begin{array}{l}\text { La iglesia está abierta al público siempre, aunque no hay culto a diario. El } \\
\text { domingo se celebra una misa bastante concurrida. } \\
\text { Dentro del culto extraordinario se destaca la celebración de bodas y el día de la } \\
\text { fiesta de la «Bendición de los frutos». }\end{array}$ \\
\hline ECONOMÍA & $\begin{array}{l}\text { La hospedería y el restaurante constituyen la principal fuente de ingresos. } \\
\text { En ambos se proporciona un servicio profesionalizado a cargo del personal } \\
\text { contratado. Los precios de las comidas se registran en la carta. El precio de la } \\
\text { habitación oscila entre los } 50 \text { y } 64 \text { euros, aunque para el } 2019 \text { está prevista una } \\
\text { subida importante. Entre las obligaciones de la empresa gestora Vicens German } \\
\text { está el pago a los franciscanos por la concesión de explotación del lugar durante } \\
\text { catorce años. El mantenimiento del santuario en las mejores condiciones y la } \\
\text { conservación del entorno natural es también un deber derivado de la concesión. }\end{array}$ \\
\hline $\begin{array}{c}\text { GESTIÓN } \\
\text { TURÍSTICA }\end{array}$ & $\begin{array}{l}\text { La gestión del Santuario de Cura es compleja, ya que es realizada por parte } \\
\text { de una empresa privada en un sitio religioso y público que, además, tiene } \\
\text { una condición de lugar singular. Un elemento a tener en consideración es la } \\
\text { afluencia de gente según la temporada y en determinadas horas del día. Esta } \\
\text { es una cuestión que debe estar bajo control, pues cuando los huéspedes están } \\
\text { en el recinto es necesario mantener un cierto nivel de silencio. Es sumamente } \\
\text { importante reducir los excesos (ruido, presencia excesiva de gente, autocares, } \\
\text { etc.) y tener una perspectiva de control, debido a que en este lugar lo que se } \\
\text { busca y lo que se oferta es precisamente paz y tranquilidad. } \\
\text { Servicios que ofertan: la hospedería/hotel y el restaurante son los servicios } \\
\text { principales, aunque también hay un centro de recepción de visitantes, salas de } \\
\text { reunión y conferencias, museo y tienda. } \\
\text { La hospedería se renovó en } 2015 \text {. Las antiguas celdas se reconvirtieron en } \\
\text { cómodas habitaciones. El nuevo hotel se promociona desde entonces como un } \\
\text { lugar confortable y de calidad para el alojamiento de turistas. Actualmente cuenta } \\
\text { con } 33 \text { habitaciones, de las cuales } 23 \text { son dobles, } 4 \text { junior suits y } 6 \text { superiores. El } \\
\text { grado de ocupación es muy elevado durante todo el año. En invierno bajan un } \\
\text { poco las reservas entre semana, pero se mantienen durante los fines de semana. } \\
\text { Entre finales de noviembre y febrero este establecimiento permanece cerrado. } \\
\text { Perfil del huésped/turista y procedencia: anteriormente el perfil mayoritario de } \\
\text { los huéspedes de Cura era el de personas religiosas que se adaptaban a la vida de } \\
\text { los franciscanos. En la actualidad - tras el abandono de la comunidad y la apertura } \\
\text { del nuevo hotel- el perfil del turista ha cambiado. Por lo general, predominan } \\
\text { los individuos o parejas de clase media que buscan relajarse en un lugar tranquilo } \\
\text { y de calidad. El santuario recibe muchos extranjeros, sobre todo alemanes. Los } \\
\text { fines de semana, principalmente en temporada baja, vienen también bastantes } \\
\text { mallorquines aprovechando las ofertas y promociones. En ocasiones, también } \\
\text { llega algún grupo con la intención de practicar turismo espiritual. }\end{array}$ \\
\hline
\end{tabular}




\begin{tabular}{|c|c|}
\hline $\begin{array}{c}\text { GESTIÓN } \\
\text { TURÍSTICA }\end{array}$ & $\begin{array}{l}\text { Estancia media: la estancia media se sitúa entre dos y tres noches. En temporada } \\
\text { alta el hotel y restaurante están siempre completos e incluso en temporada baja el } \\
\text { porcentaje de ocupación es elevado. } \\
\text { El restaurante es otro de los servicios más demandados y uno de los puntos } \\
\text { fuertes del santuario. Este se distingue por su cuidada gastronomía, que } \\
\text { además pone el acento en la cocina local. No es exclusivo para los huéspedes. } \\
\text { En ocasiones, el restaurante acoge alguna celebración especial, aunque sus } \\
\text { responsables nunca aceptan propuestas muy concurridas para no alterar la } \\
\text { tranquilidad del lugar. Los banquetes de bodas y comuniones solo se admiten si } \\
\text { el número de comensales es limitado. } \\
\text { Excursiones: el santuario es visitado por excursiones organizadas acompañadas } \\
\text { de su propio guía profesional, pero también por muchos excursionistas } \\
\text { individuales y personas procedentes de las localidades vecinas. A veces también } \\
\text { llegan cruceristas, aunque esto no es habitual ni tampoco interesa, ya que su } \\
\text { presencia masiva atentaría contra la esencia espiritual y tranquilidad del lugar. } \\
\text { Por esta misma razón, las visitas de colegios pueden también representar un } \\
\text { problema. Estas, habitualmente se programan a través del contacto con una } \\
\text { empresa de gestión turística - Spiritual Mallorca- que colabora con el } \\
\text { santuario. La tienda y el museo están también gestionados por esta empresa. En } \\
\text { la tienda se venden recuerdos del santuario y gran cantidad de souvenirs. } \\
\text { Actividades: por parte de la administración del santuario no hay una } \\
\text { programación regular de actividades. } \\
\text { Promoción: el santuario se promociona en redes sociales pero no de manera } \\
\text { intensa, debido a que tienen reservas suficientes y no lo necesitan. Las reservas } \\
\text { se hacen a través de la página web, por correo electrónico o por teléfono, } \\
\text { directamente con el santuario. También se hacen muchas reservas a través de los } \\
\text { portales digitales (Booking, Tripadvisor...). }\end{array}$ \\
\hline PATRIMONIO & $\begin{array}{l}\text { El santuario tiene condición de Bien de interés Cultural (BIC). Accesibilidad: } \\
\text { el acceso es libre y cualquier persona puede recorrer el lugar y disfrutar del } \\
\text { patrimonio siempre que respete el clima de silencio y de paz. } \\
\text { Estado de conservación: los edificios que componen el conjunto presentan un } \\
\text { buen estado de conservación. Los medios para el mantenimiento proceden de los } \\
\text { beneficios obtenidos a partir de la explotación del hotel y del restaurante. } \\
\text { La iglesia, el edificio del restaurante y la hospedería constituyen los espacios } \\
\text { más relevantes. El entorno natural que los rodea contribuye a resaltar la belleza } \\
\text { del lugar. }\end{array}$ \\
\hline $\begin{array}{l}\text { VISIÓN DE } \\
\text { FUTUROY } \\
\text { REFLEXIÓN } \\
\text { FINAL }\end{array}$ & $\begin{array}{l}\text { Turismo espiritual ¿Segmento en auge o crisis?: los gestores del Santuario } \\
\text { de Cura han apostado por el desarrollo del turismo cultural aunque reconocen } \\
\text { que el turismo espiritual es un sector que está en auge, tal y como se observa en } \\
\text { San Honorato, con quién, no obstante y a pesar de la vecindad, apenas tienen } \\
\text { relación. Consideran que la clave del éxito alcanzado en Cura viene dada por la } \\
\text { combinación de espacio sagrado y espacio de ocio, manteniendo la identidad y } \\
\text { distinguiéndose por la calidad del servicio ofrecido. Con respecto al futuro, los } \\
\text { gestores de este santuario apuestan por mejorar la oferta de ocio pero sin caer en } \\
\text { la banalización del espacio sagrado. El cumplimiento de las normas que hay que } \\
\text { guardar en un lugar de estas características (silencio, decoro en el vestir, etc.) } \\
\text { es básico para alcanzar los objetivos propuestos y es un aspecto que al equipo } \\
\text { directivo le preocupa especialmente. }\end{array}$ \\
\hline
\end{tabular}




\begin{tabular}{|c|l|}
\hline VISIÓN DE & ¿Por qué es un lugar especial?: a juicio del director, el Santuario de Cura es un \\
FUTUROY & lugar singular por dos motivos principales: por la gran tradición simbólica y por \\
REFLEXIÓN & la tranquilidad y serenidad que transmite el paisaje de montaña. La naturaleza \\
FINAL & $\begin{array}{l}\text { contribuye a engrandecer la arquitectura e invita a la meditación, razón por } \\
\text { la cual no descartan fomentar en el futuro una vía de desarrollo del turismo } \\
\end{array}$ \\
& espiritual. \\
\hline
\end{tabular}

El Santuario de Cura se ha orientado a lo largo de los últimos años al fomento del turismo cultural. La gestión religiosa continúa en manos de los franciscanos que se encargan del culto pero la gestión turística recae en una empresa privada, al frente de la cual está un director, quien considera objetivo prioritario alcanzar un equilibrio entre espiritualidad y actividad turística. Un equilibrio nada fácil de conseguir por el hecho de que en el Santuario de Cura suelen coincidir visitantes de distinta índole. No obstante, hasta el momento se ha avanzado en esta dirección intentando controlar los flujos y las actividades que realizan.

El santuario en su conjunto funciona satisfactoriamente, la valoración por parte del público es muy positiva y, además, los ingresos obtenidos gracias al turismo han permitido la conservación del patrimonio y su mantenimiento en buenas condiciones. La apuesta por la calidad y por la distinción en un marco de no masificación marca la hoja de ruta seguida por el equipo directivo que no descarta, en un futuro, apostar por el turismo espiritual. En la actualidad, el Santuario de Cura destaca por su vitalidad y dinamismo en el marco de la montaña de Randa, toda vez que es el lugar más adecuado para la práctica del turismo cultural en un entorno de gran riqueza natural desde donde se proyectan visitas a diferentes puntos de Mallorca.

\section{A MODO DE CONCLUSIÓN}

Los tres santuarios localizados en la montaña de Randa tienen modelos diferenciados de gestión y los tres - en mayor o menor medida - han introducido cambios en los últimos años para adaptarse a una nueva demanda de turistas espirituales y/o culturales. La crisis de vocaciones y la emergencia de nuevas opciones turísticas son los factores que han desencadenado las transformaciones en los modelos vigentes, con la intención de adaptarse a una nueva realidad. Turismo espiritual y cultural conviven ahora en estos lugares sagrados y sus gestores buscan la obtención de beneficios económicos tratando de garantizar la sostenibilidad de los espacios y de mantener el carácter religioso que tradicionalmente han tenido y que les ha convertido en lugares especiales.

El modelo de gestión del Santuario de Nuestra Señora Gracia, es el más austero, ya que solo permite la visita pública de forma limitada: no ofrece alojamiento, ni utiliza ningún tipo de promoción turística. La responsabilidad de la gestión recae en la persona del donado que vela por el mantenimiento del lugar evitando su banalización, aspecto que constituye la mayor ventaja, el punto fuerte del santuario. En contrapartida, la actividad cultural, religiosa y económica es bastante reducida. La religiosa se limita a la celebración de misas de manera puntual por parte de los franciscanos que se desplazan desde Llucmajor, y la cultural se centra en la organización de ciertas actividades extraordinarias con 
el fin de obtener algún beneficio económico al que se añaden los donativos recaudados. Este modelo de gestión es el más tradicional y el que ha sufrido menos cambios a lo largo del tiempo. No obstante, la crisis que afecta actualmente al lugar y la necesidad de obtención de mayores beneficios hace necesaria una transformación del modelo a corto o medio plazo.

En la ermita de San Honorato la actividad es mayor debido a la presencia permanente de una comunidad mixta (religiosos y laicos) que gestionan indistintamente la parte religiosa y económica. Sus miembros ofrecen unos servicios altamente demandados abiertos a todo tipo de prácticas espirituales. La hospedería y la organización de cursos y talleres reportan la mayor parte de los beneficios que, en un porcentaje elevado, se destinan a la conservación del patrimonio. En concreto la hospedería tiene una gran demanda como servicio que da cobertura completa a aquellas personas que buscan disfrutar de un retiro espiritual. La principal ventaja de San Honorato y el elemento diferenciador con respecto a los santuarios vecinos es que aquí se puede practicar un turismo espiritual en sentido estricto, sin interferencias, toda vez que la relación entre los huéspedes y la comunidad es muy estrecha. El éxito del lugar se relaciona con la tendencia al crecimiento del turismo espiritual tanto en una escala local como en un contexto global.

El Santuario de Nuestra Señora de Cura está más orientado al turismo cultural. A excepción de los servicios prestados por los franciscanos y centrados básicamente en la celebración de la liturgia dominical, la gestión del santuario está en manos de una empresa privada que, no obstante, no olvida que actúa en un lugar público y sagrado. Por tal motivo, los servicios turísticos (restaurante, hospedería, tienda...) están más profesionalizados y las instalaciones son de mayor calidad. La plaza del convento, la capilla, el jardín, los miradores, el museo y la cueva de Ramón Llull contribuyen a diversificar la oferta cultural y de ocio. ${ }^{6}$ Estas condiciones constituyen una ventaja para los practicantes del turismo cultural, a la vez que van en detrimento de la esencia espiritual y tradicionalmente austera del lugar.

Los tres santuarios del Puig de Randa son diferentes y diversifican la oferta sagrada de la montaña y por extensión del territorio insular. Mientras Cura y Gracia reciben a visitantes y turistas de perfil cultural, San Honorato se ha especializado en un turismo más propiamente espiritual. Aunque no hay registros oficiales que consignen el número de visitantes, los tres santuarios están muy concurridos a lo largo del año. En la medida en que aumente el número de visitas, resultará más complicado mantener la atmósfera de tranquilidad y silencio que requieren estos espacios. Por el momento, los impactos del turismo no son grandes debido a tres factores: al control ejercido por parte de los gestores de los tres centros; a que tanto las personas que se alojan en estos lugares como los visitantes de paso muestran un gran respeto por el patrimonio natural y cultural; y a que parte de los ingresos obtenidos por el desarrollo de la actividad turística se reinvierten en su mantenimiento y conservación.

La apuesta por la calidad y por la singularidad en un marco de espiritualidad y de paz marca la hoja de ruta seguida por los santuarios de la montaña de Randa. En la variedad de ofertas y en la búsqueda de la sostenibilidad del entorno físico y medioambiental

6 Véase página del Santuario de Cura [En línea: http://www.santuaridecura.com, consulta: 15-09-2018]. 
reside la riqueza de esta montaña que puede consolidarse como punto destacado del turismo religioso y espiritual mallorquín. El reto de futuro que se presenta a sus gestores es el de salvar la dificultad de dirigir el volumen creciente de visitantes manteniendo un equilibrio entre la necesidad de preservación de estos lugares y la provisión de una alta calidad experiencial.

\section{REFERENCIAS BIBLIOGRÁFICAS}

AULET SERRALLONGA, S. (2012): Competitivitat del turismo religiós en el marc contemporani. Els espais sagrats $i$ el turismo. Tesis doctoral. Girona, Universitat de Girona. [En línea: goo.gl/4B2wdX, consulta: 07-02-2018].

AULET SERRALLONGA, S. y HAKOBYAN, K. (2011): «Turismo religioso y espacios sagrados: una propuesta para los santuarios de Catalunya». Revista Iberoamericana de Turismo, $\mathrm{n}^{\mathrm{o}} 1$, pp. 63-82.

BAHAMONDES GONZÁLEZ, L, DIESTRE DE LA BARRA, F., MARÍN ALARCÓN, N. y RIQUELME MAULÉN, W. (2017): «Espiritualidad y territorio: la emergencia de nuevos mercados religiosos en Pisco Elgui (IV Región, Chile)». Revista de Estudios Sociales, $\mathrm{n}^{\circ}$ 61, pp. 69-84.

BAHAMONDES GONZÁLEZ, L. (Ed.) (2013): Transformaciones y alternativas religiosas en América Latina. Santiago de Chile, L. Bahamondes G.

BASTIAN, J.P. (1997): La Mutación Religiosa en América Latina. Para una sociología del cambio social en la modernidad periférica. México, Fondo de Cultura Económica.

BAUZÁ MARTORELL, F.J. (2016): La experiencia eremítica en Mallorca y sus antecedentes históricos. Palma, José J. de Olañeta.

COHEN, E. (1992): «Pilgrimage centers: Concentric and Excentric». Annals of Tourism Research, $\mathrm{n}^{\circ} 19$ (1), pp. 33-50.

DAVIE, G. (2005): «From obligation to Consumption a Framework for Reflection in Northern Europe». Political Theology, n 6, pp. 281-301.

DAVIE, G. (2011): Sociología de la religión. Madrid, Akal.

FORTEZA OLIVER, M. (2016): Xilografies antigues del Bt. Ramón Llull. Palma de Mallorca, Museu Diocesà de Mallorca i Capítol de la Catedral de Mallorca.

LANQUAR, R. (2007): «La nueva dinámica del turismo religioso y espiritual», Resumen del informe general de la OMT preparado por el autor en el contexto de la Conferencia internacional de Córdoba «Turismo y Religiones: una contribución al diálogo de religiones, culturas y civilizaciones», OMT, 29-31 de octubre de 2007.

MARTÍNEZ CÁRDENAS, R. (Coord.) (2009): Dimensionamiento del turismo espiritual en México. México, D. F., Secretaría de Turismo (SECTUR).

MARTÍNEZ CÁRDENAS, R. (Coord.) (2012): «Propuesta metodológica para la conceptualización dinámica del turismo espiritual», en Turismo Espiritual II. Una visión iberoamericana. México, Universidad de Guadalajara, pp. 9-14.

McGETTIGAN, F. (2003): «An analysis of cultural tourism and its relationship with religious sites», en Religious, tourism and pilgrimage. Fátima, ATLAS, pp. 13-26

MUNAR, G. (1973): La muntanya dels tres santuaris. Llucmajor, Edicions L'Angel Pastor. 
MUNAR, G. (1973). El santuari de Ntra. Senyora de Cura. Llucmajor, Edicions L'Angel Pastor.

MUNAR, G. (1974): El santuari de Ntra Senyora de Gracia. Llucmajor, Edicions L'Angel Pastor.

NOVO MALVÁREZ, M. (2016): Los conventos de clausura del centro histórico de Palma. Potencialidades y nuevos usos vinculados a la gestión de su patrimonio cultural. Tesis doctoral. Palma de Mallorca, Universitat de les Illes Balears. [En línea: goo. gl/Lnnf3y, consulta: 07-02-2018].

PETRILLO, C. S. (2003): «Management of churches and religious sites», en Religious tourism and pilgrimage. Fátima, ATLAS, pp. 71-86.

PLAFFENBERGER, B. (1983): «Serious pilgrims and frivolous tourist». Annals of Tourism Research, $\mathrm{n}^{\circ} 10$ (1), pp. 57-74.

RINSCHEDE, G. (1992): «Forms of religious tourism». Annals of Tourism Research, vol. 19 (1), pp. 51-67.

SEBASTIÁN, S. (1968): «La iconografía de Ramón Llull en los siglos XIV y XV». Mayurca, 1, pp. 25-62.

VEGA-CENTENO, I. (1995): «Sistemas de creencias. Entre la oferta y demanda simbólicas». Revista Nueva sociedad, nº 136, pp. 56-69.

UN ERMITAÑO (1965): Mallorca eremítica. Palma de Mallorca, [s.n.], Imp. Sagrados Corazones.

VUKONIC, B. (1992): «Medjugorje's religion and tourism connection». Annals of Tourism Research, vol. 19 (1), pp. 79-91. 